\title{
Kaempferitrin Cause Cell Cycle Arrest at G2/M Phase and Reactive Oxygen Species Mediated Apoptosis in Human Colon Cancer HT-29 Cells
}

\author{
Mydhili Govindarasu, Kalaiyarasu Thangaraj, Venkatachalam Murugesan, Manju Vaiyapuri
}

Abstract: Kaempferitrin (Kaempferol-3,7-O-bisa-L-rhamnoside) belongs to a group of metabolites known as flavonoids. Kaempferitrin has been proven to have a wide range of important pharmacological activities, such as antioxidant, anti-inflammatory, anti-angiogenic and anti-carcinogenic activity. Current technologies dealing with drug discovery could provide the data necessary to consider kaempferitrin and its analogs as safe drugs for use in humans. The MTT test showed that colon cancer HT-29 cell viability was reduced dose-dependently with an increased kaempferitrin concentration. The fifty percent inhibition concentration $\left(I C_{50}\right)$ of kaempferitrin was found to be $30.0 \mu \mathrm{M}$, which can cause programmed cell death in HT-29 cells and enhance the levels of reactive oxygen species (ROS). After kaempferitrin treatment, apoptosis was observed in a dose-dependent manner 7.5, 15.0, and $30.0 \mu \mathrm{M}$, respectively. Excessive intracellular reactive oxygen species damaged cellular structures and led to cell death. The relation of ROS with kaempferitrin-induced apoptosis in HT-29 cells was analyzed by flow cytometry.

Keywords: apoptosis, cell cycle arrest, colon cancer, kaempferitrin

\section{INTRODUCTION}

Colorectal cancer (CRC) is the most common neoplasm and also the fourth most lethal cancer worldwide, accounts for about $10 \%$ of total cancer-related deaths (Kalaiyarasu et al., 2018). In United States, $1,762,450$ new cancer cases were reported out of which 606,880 Americans were predicted to die in 2019, which is almost 1,700 deaths per day. The highest numbers of death are due to cancer in lung, prostate and colorectum in men and in lung, breast, and colorectum in women (Siegel et al., 2019). Futuristic molecular therapeutic strategies, capable to destroy some restrictions are pivotal

Revised Manuscript Received on October 25, 2019

Mydhili Govindarasu ${ }^{1}$, Venkatachalam Murugesan $^{1}$ and Manju Vaiyapuri ${ }^{1 *}$, Molecular Oncology Lab, Department of Biochemistry, Periyar University, Salem, Tamil Nadu, India-636011; mydhilibc12@gmail.com

Kalaiyarasu Thangaraj ${ }^{\mathbf{1}, 2}$, Department of Microbiology and Biotechnology, Bharath Institute of Higher Education and Research, Chennai, Tamil Nadu, India- 600045 ; kalaiarasu2787@gmail.com entail for prospect advantageous management of colorectal cancer (AlShamaileh et al., 2017). Carcinogenesis is the outcome of a network interchange of cell-intrinsic along with cell-extrinsic development to facilitate sustained proliferation, apoptosis resistance (West et al., 2015). The main causes of colorectal cancer include eating processed meat and red meat, obesity, smoking and drinking, aging, the history of inflammatory bowel diseases, chronic intestinal inflammation and genetic variations contributing to the inherited CRC, genetic aberrations including deprivation or mutations in tumor suppressor genes, family adenomatous polyposis (FAP) (Zhang et al., 2016) genetic reorganization controlling cell survival, angiogenesis cell proliferation, inflammation in addition participate significant chore in colon cancer (Rupnarain et al., 2004).

Metastatic CRC has been treated with 5-fluorouracil, which is a well known choice of chemotherapy drug for many years, and a number of new targeted drugs such as humanized monoclonal antibodies to EGFR or anti-VEGFR are being recently used in the treatment of CRC patients (Derangère et al., 2016). Increased ROS generation in cancer cells plays a key role in the unimpeded progression, proliferation of the cell cycle, interruption of apoptosis signaling and cell survival. The cell cycle proteins are closely involved in the control points and in the apoptosis instructions (Evan et al., 1995). Oxidative stress was caused by the overproduction of reactive oxygen species and/or reduction in antioxidant defense systems. When the redox systems are imbalanced, this causes damage to macromolecules that can affect whole organisms negatively.

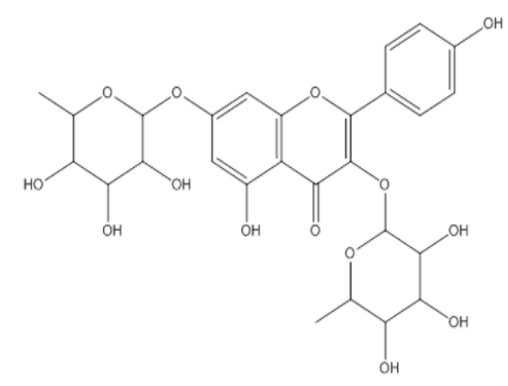

Figure 1. Kaempferitrin

((Kaempferol-3-7-O-bis- $\alpha$-L-rhamnoside), Molecular weight-578.52 $\mathrm{g} / \mathrm{mol}$ ) 


\section{Kaempferitrin Cause Cell Cycle Arrest at G2/M Phase and Reactive Oxygen Species Mediated Apoptosis in Human Colon Cancer HT-29 Cells}

Flavonoids which originate from a hefty series of compounds are found in numerous nutritional floras and consequently, they formulate a salient part of the diet. Flavonoids are used in biological activities including cytotoxic and anti-tumor effects (Chen et al., 2005). Successful alleviation of chemotherapeutic agents, usually dependent upon their cell growth and/or differentiation skills (Vijayalakshmi et al., 2017). Kaempferol a natural polyphenol, recognized for its anti-oxidant property along with anti-inflammatory feature, is obtained from variety of vegetation including beans, broccoli, berries, green teas, strawberries, grapes, apples, citrus fruits, onions etc with various pharmacological corollary (Varshney et al., 2018). Kaempferol is an effective drug against myocardial infarction, thromboembolic diseases, osteogenic, neuroprotective, atrial fibrillation and ischemic heart disease (Xu et al., 2015), later reports showed the anti-obesity and hypoglycemic effect of kaempferol when tested over high fat diet mice (Liao et al., 2016). Kaempferitrin (Figure 1.) was also able to inhibit the activity of MPO, leukocyte migration, levels of nitric oxide and interleukin-17A in the pulmonary pleurae of mouse (Koelzer et al, 2009). Kaempferitrin's anti-tumor function is arbitrated using a variety of methods, along with anti- proliferation, ROS generation, apoptosis induction, cell cycle arrest, and anti- metastasis/antiangiogenesis. The current research perceives the stimulating cell cycle arrest of kaempferitrin in HT-29 colon cancer cells.

\section{Materials and Methods}

\subsection{Chemicals}

DMEM (Dulbecco's Modified Eagle's medium) was obtained from InVitrogen GibcoBRL. 3-(4,5-Dimethyl-2-thiazolyl)-2,5-diphenyl-2H-tetrazolium bromide (MTT), fetal bovine serum (FBS), DMSO (dimethyl sulfoxide $\left.\left(\mathrm{CH}_{3}\right)_{2} \mathrm{SO}\right)$, Trypsin-Ethylenediaminetetraacetic acid (EDTA), 4',6-diamidino-2-phenylindole (DAPI), acridine orange $(\mathrm{AO})$, ethidium bromide $(\mathrm{EtBr})$, propidium iodide (PI), formazan blue (1-(4,5-Dimethylthiazol-2-yl)-3, 5-diphenylformazan), and kaempferitrin (KM) were purchased from Sigma-Aldrich Chemical Company (USA).

\subsection{Colon Cancer HT-29 Cell Lines}

Human colon adenocarcinoma cell lines (HT-29) were obtained from NCCS (National Centre for Cell Science) Pune, India. HT-29 cell lines were perpetuated in DMEM (GIBCO BRL) accompaniment with $10 \%$ fetal bovine serum (FBS) (Gibco-BRL) in addition to $2 \mathrm{mM}$ L-glutamine (Sigma-Aldrich Chemical Company), penicillin $(100 \mathrm{U} / \mathrm{mL})$ combined with streptomycin $(100 \mu \mathrm{g} / \mathrm{mL})$ and perpetuated at room temperature $\left(37^{\circ} \mathrm{C}\right)$ in an atmospheric condition of $5 \%$ $\mathrm{CO}_{2}$ in the cell culture incubator humidified with $95 \%$ air. Kaempferitrin stock solution was formulated with dimethyl sulfoxide $(0.1 \%)$ and stored at $-20^{\circ} \mathrm{C}$ for further use.

\subsection{MTT Assay}

HT-29 colon adenocarcinoma cancer cells and FHC (human fetal normal colonic mucosa) were treated with kaempferitrin $(0,1.875,3.75,7.5,15.0,30.0$ and $100 \mu \mathrm{M})$. To determine the cell viability, we used tetrazolium dye (MTT, Sigma), following the method depicted earlier (Karthi et al., 2016). In brief, the HT-29 cells and FHC cells were seeded in 96-well plates $\left(4 \times 10^{3}\right.$ cells/well), cultured and allowed to adhere overnight. Following incubation for $24 \mathrm{hr}$, as soon as the cells acquired typical confluency, the supernatant medium was replenished using different concentrations of kaempferitrin in complete medium and DMSO for $24 \mathrm{hr}$. At the end of each treatment, the medium in the well was removed and $50 \mu 1 \mathrm{MTT}$ reagent (concentration $0.5 \mathrm{mg} / \mathrm{mL}$ ) was added. Afterward, the wells were kept in a dark place for $4 \mathrm{hr}$ at $37^{\circ} \mathrm{C}$. Medium with MTT was discarded and $200 \mu \mathrm{L}$ DMSO was added to solubilize the formazan blue (1-(4,5-Dimethylthiazol-2-yl)-3,5-diphenylformazan)

crystals. The percentage viability was measured at $570 \mathrm{~nm}$ using an ELISA plate reader.

\subsection{Acridine Orange Ethidium Bromide (AO/EtBr) Double Staining}

A quantity of $4 \times 10^{3}$ cells $/ \mathrm{mL}$ was seeded in 96 -well plates and treated with kaempferitrin for $24 \mathrm{hr}$. Then, the cells were centrifuged at $3000 \mathrm{~g}$ for $10 \mathrm{~min}$. A total of $100 \mu \mathrm{L}$ of acridine orange $(100 \mathrm{mg} / \mathrm{mL} \mathrm{AO})$ and $100 \mu \mathrm{L}$ ethidium bromide $(100 \mathrm{mg} / \mathrm{mL} \mathrm{EtBr})$ were added to each well. After 2-3 min of incubation, the cells were visualized under a fluorescence microscope (Nikon Eclipse, Japan) with an excitation filter at wavelength of 510 to $590 \mathrm{~nm}$ and with $40 \times$ magnification (Vivek et al., 2012).

\subsection{Flow Cytometric Analysis}

To analyze the efficacy of the drug on the cell cycle phase distribution, HT-29 cells $\left(1 \times 10^{5}\right.$ cells $\left./ \mathrm{mL}\right)$ were treated with kaempferitrin and cultured for $24 \mathrm{hr}$. The kaempferitrin-treated $(7.5,15.0$, and $30 \mu \mathrm{M})$ HT-29 cells were harvested and then washed with PBS and fixed in $70 \%$ ice-cold ethanol at $4^{\circ} \mathrm{C}$ overnight. The cells were washed twice with cold PBS and suspended in the combined solution of $0.1 \mathrm{mg} / \mathrm{mL}$ of RNase A and $40 \mu \mathrm{g} / \mathrm{mL}$ of PI. Then, the suspension was gently shaken at $37^{\circ} \mathrm{C}$ for $30 \mathrm{~min}$ (Krishan et al., 1975). HT-29 cells $(10,000)$ were investigated at various concentrations by flow cytometry on the FL2-A detectors and analyzed using the statistical records which were calculated utilizing BD Cell Quest Pro Software (version 6.0) to determine the $\%$ of cells in apoptosis, Sub- $\mathrm{G}_{0}, \mathrm{G}_{0} / \mathrm{G}_{1}, \mathrm{~S}$ and $\mathrm{G}_{2} / \mathrm{M}$ phases. 


\section{6. \\ Annexin \\ V-Fluorescein \\ Isothiocyante (FITC)/Propidium Iodide (Annexin V-FITC/PI) Apoptotic Assay}

Annexin V-FITC/PI dual staining was used to detect early and late apoptotic cells. In brief, colon adenocarcinoma HT-29 cells were seeded in a 6 -well plate $\left(4 \times 10^{3}\right.$ cells $\left./ \mathrm{mL}\right)$ and treated with kaempferitrin $(7.5,15.0$, and $30.0 \mu \mathrm{M})$ for 24 hr. Both the floating and adherent cells were harvested, pooled together and washed with PBS. A total of $1 \times 10^{6}$ cells/mL was then resuspended in $1 \mathrm{X}$ Annexin $\mathrm{V}$ binding buffer. Subsequently, $100 \mu \mathrm{L}$ of solution was taken in a tube and then, $5 \mu \mathrm{L}$ of FITC Annexin V and $5 \mu 1$ of PI were added. After gentle vortexing, the solution was then incubated for 15 min over ice in the dark. A quantity of $400 \mu \mathrm{L}$ of $1 \mathrm{X}$ binding buffer was added to each tube. The cells were counted using a fluorescence image cytometer within $1 \mathrm{hr}$ (Becton-Dickinson, San Jose, CA) (Phang et al., 2016).

\subsection{ROS Detection}

Intracellular ROS accumulation was analyzed by ROS assay kit (Byotime Biotech) that utilizes 2', 7'-dichloroflurescin diacetate (DCFH-DA) - a fluorogenic dye. The principle behind ROS accumulation is that, DCFH-DA penetrates the cell membrane freely and is hydrolyzed by esterase into DCFH, which cannot escape from the cell; subsequently, reactive oxygen species further oxidizes DCFH to DCF, which is a fluorescent brilliant green. Kaempferitrin-treated cells were nurtured with $10 \mu \mathrm{M}$ DCFH-DA for $20 \mathrm{~min}$ at $37^{\circ} \mathrm{C}$. The intracellular ROS were analyzed by flow cytometry. The fluorescence intensity reflected the amount of reactive oxygen species generated; an increase in fluorescence intensity represents an enhanced generation of ROS (Miki et al., 2012).

\subsection{Statistical Analysis}

All data in this study were presented as mean \pm standard deviation. Statistical analysis of the data was performed by one-way analysis of variance (ANOVA), followed by Tukey's multiple range tests for post-hoc analysis in Sigma Stat Version 3.5 software. The significance level was set at $\mathrm{p}<0.05$.

\section{RESULTS}

\subsection{Kaempferitrin Showed Cytotoxicity against HT-29 Cells}

HT-29 cell line treated with various concentrations ( 1.875 to $100 \mu \mathrm{L}$ ) of kaempferitrin for $24 \mathrm{hr}$ exhibited dose-dependent inhibition of cell viability(Figure 2). The percentage cell viability was calculated as the percentage absorption of cells treated with the control cells. The fifty percent inhibition concentration $\left(\mathrm{IC}_{50}\right)$ of kaempferitrin was found to be $30.0 \mu \mathrm{M}$ for $24 \mathrm{hr}$, as shown in Figure 2A.

Furthermore, to evaluate the cytotoxic activity of kaempferitrin on normal colon cell lines (FHC, human fetal normal colonic mucosa), the FHC cells were treated with different concentrations of kaempferitrin for about $24 \mathrm{hrs}$.

The results of cell cytotoxicity assay are shown in Figure 2B. There is no appreciable reduction in the cell viability after incubation for $24 \mathrm{hr}$, indicating that kaempferitrin is an effective drug for colon cancer. These results clearly conclude that kaempferitrin potentially affects cancer cells (HT-29), compared to the normal FHC cells.
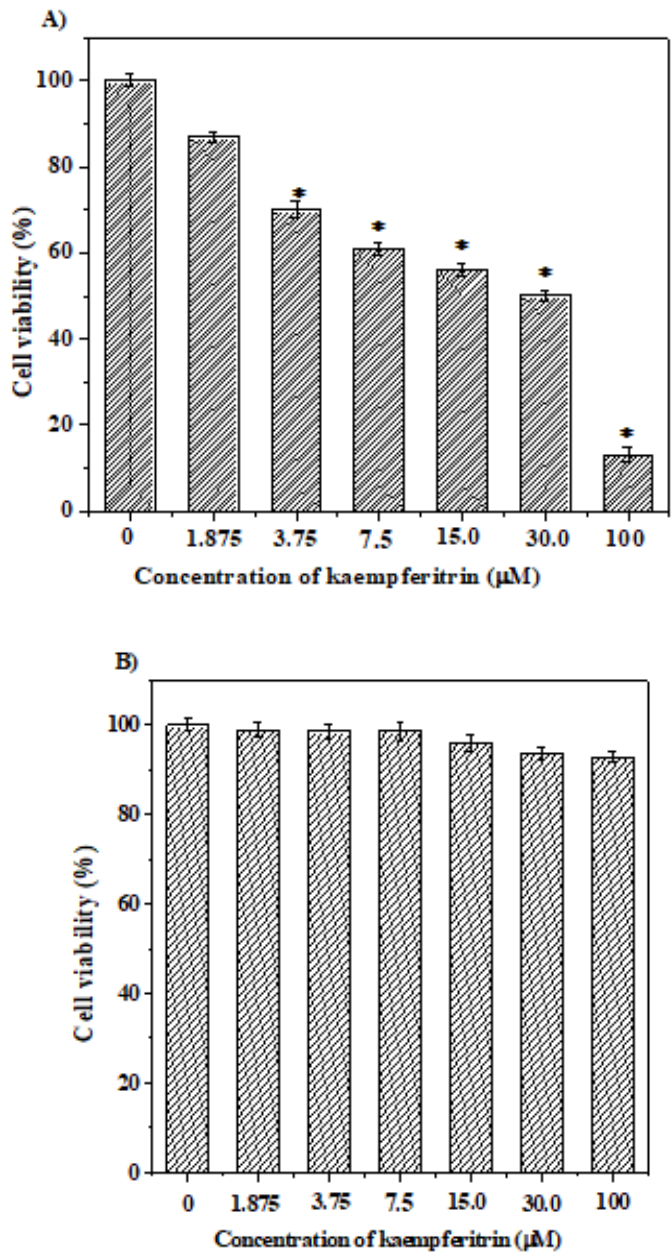

Figure 2(A). The cytotoxicity of kaempferitrin on HT-29 was evaluated by MTT assay. (B) The cytotoxicities of kaempferitrin on normal colon cell lines (FHC). Data presented are the mean \pm standard deviation of the results of three independent experiments $(* P<0.05)$.

\subsection{AO/EtBr Dual-Staining Assay}

HT-29 cells were stained with fluorescent coloring agent $\mathrm{AO} / \mathrm{EtBr}$ was utilized to assess the morphology of apoptotic nuclei. Three concentrations (7.5, 15.0 and 30.0 $\mu \mathrm{M}$ ) for kaempferitrin were preferred, according to the $\mathrm{IC}_{50}$ values determined by cytotoxicity assay. As a result, cell death and morphological fluctuations of HT-29 cells began with kaempferitrin staining using $\mathrm{AO} / \mathrm{EtBr}$. AO is made up of equally viable and non-viable cells and emanates green fluorescence when interpolated to dual-standard DNA and EtBr is only accumulated by non-viable

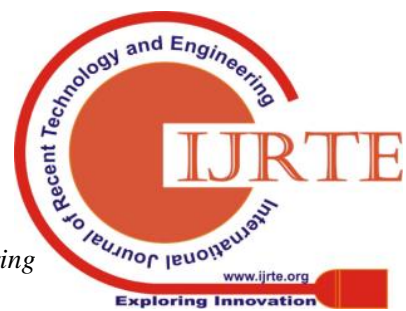




\section{Kaempferitrin Cause Cell Cycle Arrest at G2/M Phase and Reactive Oxygen Species Mediated Apoptosis in Human Colon Cancer HT-29 Cells}

cells and emits red fluorescence through interaction with DNA. HT-29 cells treated with kaempferitrin were examined under an inverted microscope after $24 \mathrm{hr}$. Figure 3 shows nuclear chromatin condensation and blebbing in kaempferitrin-treated cells, which indicated reduced apoptosis. At the same time, no observable apoptosis was present in the control group and cells were in the form of intact green nuclei (Figure 3a). Furthermore, in HT-29 cells, the granular yellowish green AO nuclear staining was detected earlier and at the late stage of apoptosis (Figure $3 \mathrm{~b}-\mathrm{d})$. While increasing the concentration of $30.0 \mu \mathrm{M}$ kaempferitrin for the treatment of colon cancer cells, the amount of early-apoptotic (EA) and late-apoptotic (LA) cells were also increased.

A)
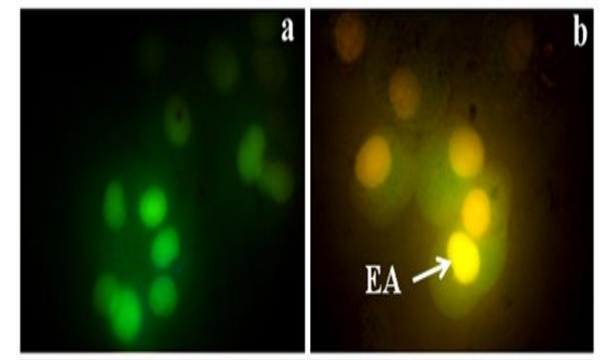

B)
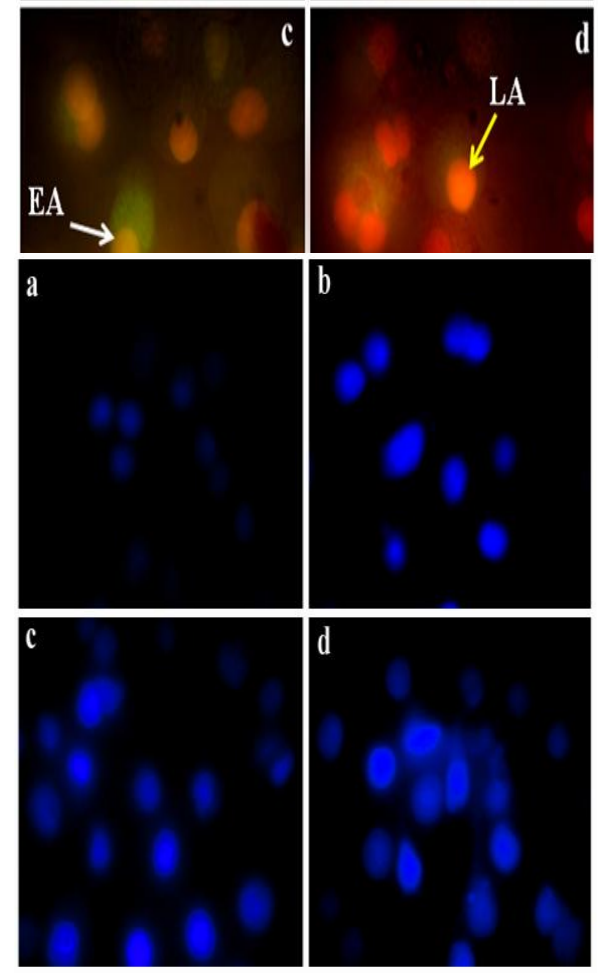

Figure 3 (A). Fluorescence microscopic images of acridine orange/ethidium bromide ( $\mathrm{AO} / \mathrm{EtBr}$ ) staining for apoptosis in colon cancer HT-29 cells. a) Control cells show signs of a normal structure, without any features of apoptosis and necrosis. b) HT-29 cells treated with $7.5 \mu \mathrm{M}$ of kaempferitrin show early-apoptotic (EA) cells. c) HT-29 cells treated with $15.0 \mu \mathrm{M}$ of kaempferitrin, show early-apoptotic cells. d) HT-29 cells treated with $30.0 \mu \mathrm{M}$ of kaempferitrin. These images were taken by fluorescence microscopy. After $24 \mathrm{hr}$ of $30.0 \mu \mathrm{M}$ kaempferitrin treatment, cells stained with orange represent late apoptosis (LA). (B)Morphological evidence of apoptosis in HT-29 cells after $24 \mathrm{hr}$ of kaempferitrin treatment by 4', 6-diamidino-2-phenylindole (DAPI) staining.

\subsection{Cell Cycle Phase Analysis}

To study the efficacy of kaempferitrin on HT-29 cells, the cell cycle phase distribution was analyzed using flow cytometric analysis. Antitumor efficacy of kaempferitrin on colon cancer cells, and the cell cycle phase distribution is shown in Figure 4. HT-29 cells treated with a controlled concentration of $7.5 \mu \mathrm{M}, 15.0 \mu \mathrm{M}$ and $30.0 \mu \mathrm{M}$ for $24 \mathrm{hr}$. At lower doses of kaempferitrin $(7.5 \mu \mathrm{M})$, the number of HT-29 cells during the G0/G1 phase was increased. The results revealed that kaempferitrin induced cell cycle arrest at the G2/M phase. Thus, with the flow cytometry observation, kaempferitrin is said to induce cell cycle arrest in the HT-29 cells.
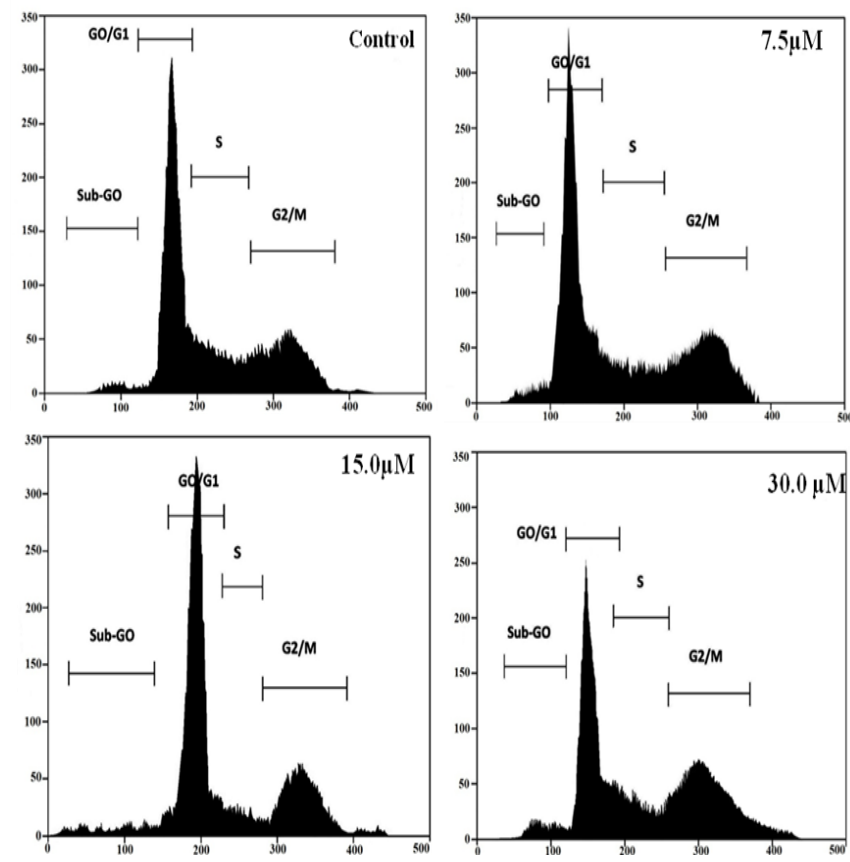

Figure 4. Apoptotic effect of kaempferitrin on cell cycle phase distribution colon cancer cells. HT-29 cells incubated with kaempferitrin $(0,7.5,15.0,30.0 \mu \mathrm{M})$ for $24 \mathrm{hr}$. DNA content of HT-29 was evaluated and the cell cycle (Sub- $G_{0} / G_{1}, G_{0} / G_{1}, S$ and $\left.G_{2} / M\right)$ phase distribution was quantified using flow cytometry. The untreated

HT-29 cells in $0.5 \%$ dimethyl sulfoxide served as a control.

\subsection{Annexin V-FITC/PI Apoptotic Assay}

Kaempferitrin was used as an anti-cancer agent against HT-29 cancer cells. Kaempferitrin-treated HT-29 cells underwent apoptosis-mediated cell death. Concerning this, the mechanism of kaempferitrin whereby it induces the death of colon cancer HT-29 cells was analyzed using Annexin V-FITC/PI staining. Kaempferitrin is a powerful inducer of DNA

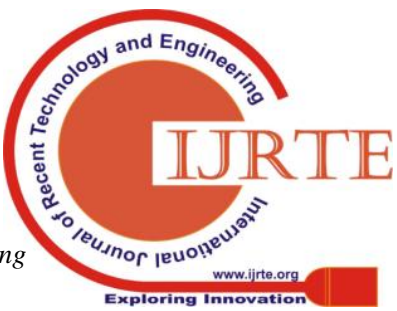


fragmentation in HT-29 colon cancer cells that causes genetic material fragmentation of treated HT-29 cells and considerably affects the morphology of cells (Figure 5A). In Figure 5A (a), control cells show round nuclei with similar chromatin and are a light-green color. Figure 5 A (b, c) revealed early-apoptotic cells (EA) at different concentrations of kaempferitrin $(7.5 \mu \mathrm{M}$ and $15.0 \mu \mathrm{M})$. The $30.0 \mu \mathrm{M}$ kaempferitrin-treated cells shown in Figure 5A (d) are small in terms of their nucleus, exhibit cytoskeletal disruption, reduction in chromosome condensation, cell shrinkage and genetic material fragmentation (late apoptotic cells (LA)).
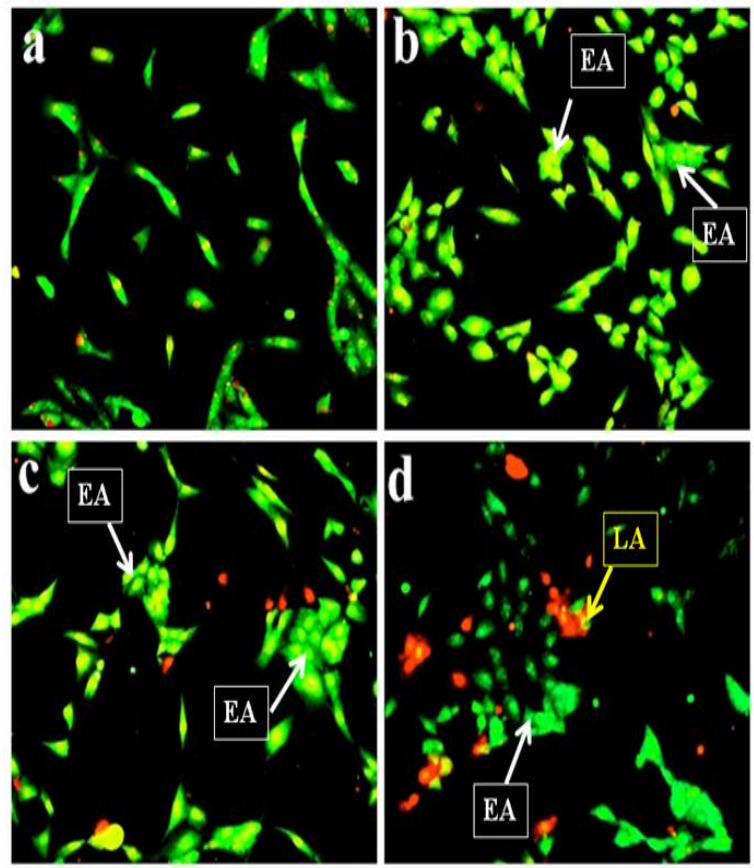

Figure 5. Apoptotic induction of kaempferitrin in HT-29 cells by Annexin V-FITC/PI apoptotic assay. a) Untreated HT-29 cells (control), b) HT-29 cells treated with $7.5 \mu \mathrm{M}$ of kaempferitrin early-apoptotic (EA) cells are shown by a white arrow, c) HT-29 cells treated with $15.0 \mu \mathrm{M}$ of kaempferitrin - the early and late-apoptotic (LA) cells are shown by white and yellow arrows, respectively, d) HT-29 cells treated with $30.0 \mu \mathrm{M}$ of kaempferitrin-late-apoptotic (LA) cells are shown by a yellow arrow.

\subsection{Kaempferitrin induces ROS Accumulation in Colon Cancer HT-29 Cells}

In the present study, the accumulation of ROS in HT-29 cells was evaluated using DCFH-DA staining by flow cytometry. Flow cytometry illustrated the frequency spectrum shift of scintillation (fluorescence) curves formed after kaempferitrin treatment, which represented a considerable increase in the cellular ROS level in HT-29 cells (Figure 6). ROS are the predominant reactive molecules, which generate a wide range of reactions, depending on the magnitude present. The cellular redox balance plays a pivotal role in the progression of multiple cancers; however, it remains arguable whether ROS could be a direct target for cancer treatment.
Cancer cells have generally higher levels of ROS due to increased metabolism and mitochondrial malfunction (Kumari et al., 2017). Increased ROS levels are usually destructive and may induce either necrosis or apoptosis; a decreased level of ROS promotes the proliferation of cells, whereas intermediary ROS levels may lead to cell differentiation and arrest of apoptotic cells (Zhu et al., 2018). It was also shown that kaempferitrin induces ROS in colon HT-29 cells. Cells were treated with $30.0 \mu \mathrm{M}$ kaempferitrin to test whether it slows down the proliferation of HT-29 cells in the presence of ROS. The findings revealed that kaempferitrin increases ROS levels in colon cancer cells.

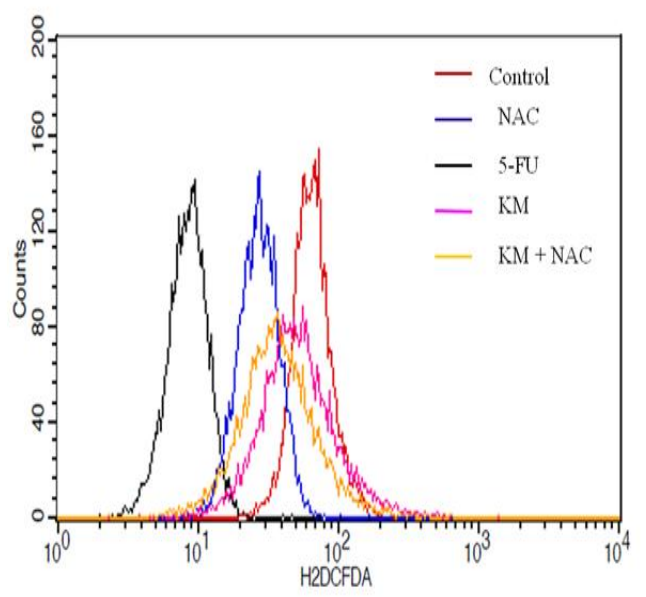

Figure 6: Kaempferitrin triggers reactive oxygen species (ROS) generation in HT-29 cells. Colon cancer cells were pretreated with N-Acetylcysteine (NAC $(5 \mu \mathrm{M}))$ alone and then incubated with Kaempferitrin $(\mathrm{KM}-30 \mu \mathrm{M})$ for $24 \mathrm{hr}$. HT-29 Cells treated with 5-fluoro uracil (5 FU), and then HT-29 cells treated with KM + NAC, respectively. HT-29 cells were incubated with DCFH-DA for $24 \mathrm{hr}$ and then analyzed by flow cytometry. The values represented the mean $\pm \mathrm{SD}$ of independent triplicates. The significance level was set at $p<0.05$.

\section{DISCUSSION}

Colon cancer is one of the deadliest and most common types of gastrointestinal cancer (Pelicano et al., 2004). The results from the current study show that kaempferitrin has significant anti-cancer effects on colon cancer cells; the $\mathrm{IC}_{50}$ value was found to be $30.0 \mu \mathrm{M}$. In this study, kaempferitrin showed decreased cell viability against HT-29 cell lines, whereas no appreciable reduction of cell viability was observed in FHC cells. ROS are the predominant reactive molecules, which generate a wide range of reactions, depending on the magnitude present. The cellular redox balance plays a pivotal role in the progression of multiple cancers; however, it remains arguable whether ROS could be a direct target for cancer

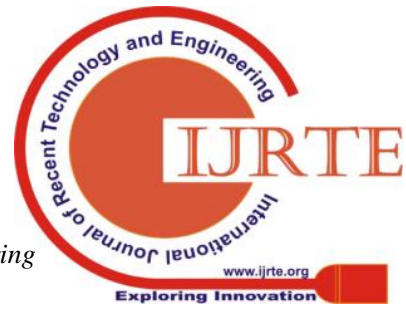




\section{Kaempferitrin Cause Cell Cycle Arrest at G2/M Phase and Reactive Oxygen Species Mediated Apoptosis in Human Colon Cancer HT-29 Cells}

treatment. Cancer cells have generally higher levels of ROS due to increased metabolism and mitochondrial malfunction (Zhu et al., 2018).

To date, the chemico-biological and pharmacological properties of the flavanoid kaempferitrin have not been completely evaluated; thus, available statistics regarding their biological activity are inadequate. In the present study, the anti-carcinogenic effects of kaempferitrin were predetermined by cell viability assay. The results of the study demonstrated that the kaempferitrin exhibited antiproliferative activity against HT-29, confirming its cytotoxic susceptibility. Figure 2A shows fifty percent cell viability $\left(\mathrm{IC}_{50}\right)$ of kaempferitrin against HT-29 on overnight treatment, which was calculated as $30.0 \mu \mathrm{M}$.

Furthermore, staining with $\mathrm{AO} / \mathrm{EtBr}$ solution of live cells presents green nuclei, showing that their cell membrane is intact. After treatment with 7.5, 15.0 and $30.0 \mu \mathrm{M}$ concentrations of kaempferitrin, the number of early-apoptotic cells increased, as shown in Figure 3c. The $\mathrm{AO} / \mathrm{EtBr}$ and DAPI staining confirmed that kaempferitrin induces significant apoptosis in a dose-dependent manner.

The current research confirmed, using flow cytometric analysis, that kaempferitrin induces cell death in HT-29 cells. The obtained data are also in agreement with the findings of Beberok et al., when the cells were treated with 7.5, 15.0 and $30.0 \mu \mathrm{M}$ of kaempferitrin, respectively. The efficacy of kaempferitrin on the cell cycle phase distribution (Figure 4) at the $\mathrm{G} 2 / \mathrm{M}$ phase cell cycle arrest is evidenced by flow cytometry.

The current study shows that excess ROS production and cellular redox balance play a vital function in the progression of cancer and also, in cell death (Figure 6). The results are consistent with those reported by Miki and Funato, who reported that cancer cells usually have higher ROS levels due to increased metabolism and mitochondrial malfunction (Miki et al., 2012). Apoptosis is a programmed cell death that maintains the cell balance. If the cell balance is disturbed, uncontrolled cell growth occurs. The excessive production of free radicals is a well known factor that may lead to apoptosis in cellular pathways. Our data suggest that kaempferitrin selectively kills cancer cells through the accumulation of ROS only in cancer cells.

\section{CONCLUSION}

To conclude, the results show that kaempferitrin is able to induce apoptosis in colon adenocarcinoma HT-29 cells in a concentration-dependent manner, without having toxic effects on normal cells. Kaempferitrin inhibits HT-29 cell viability in this study and $\mathrm{AO} / \mathrm{EtBr}$ staining reveals morphological characteristics of cell apoptosis induced by kaempferitrin. Certainly, kaempferitrin-induced cell cycle arrest is observed in the G2/M phase. Finally, ROS play an important role in apoptotic cell death in HT-29 cells. Since it is non-toxic, inexpensive and has good bioavailability, it is concluded that kaempferitrin has great potential in cancer prevention. Above all, this study elucidated that kaempferitrin has beneficial therapeutic properties and suggests that kaempferitrin could be used as a functional complementary medicine for colon cancer. However, further studies are required in order to understand the complete mechanism of action of the compound.

Funding: This research received no external funding. The authors especially thankful for the technical support from Department of Biochemistry, Periyar University, Salem,

Tamil Nadu, India.

Conflicts of Interest: The authors declare no conflict of interest.

\section{REFERENCES}

1. AlShamaileh, H.; Wang, T.; Xiang, D.; Wang, Y.; Ha-Lien Tran P. Barrero, R.B.; Zhang. P.; Li, Y.; Kong, L.; Liu, K.; Zhou, S.; Hou, Y.; Shigdar, S.; Duan. W. Aptamer-mediated survivin RNAi enables

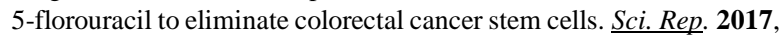
7(1), 5898. DOI:10.1038/s41598-017-05859-z.

2. Beberok, A.; Rzepka, Z.; Respondek, M.; Rok, J.; Sierotowicz, D.; Wrześniok, D. GSH depletion, mitochondrial membrane breakdown, caspase-3/7 activation and DNA fragmentation in U87MG glioblastoma cells: new insight into the mechanism of cytotoxicity induced by fluoroquinolones. Eur. J. Pharmacol. 2018, 835, 94-107. https://doi.org/10.1016/j.ejphar.2018.08.002.

3. Chen, D.; Daniel, K.G.; Chen, M.S.; Kuhn, D.J.; Landis-Piwowar, K.R.; Dou, Q.P. Dietary flavonoids as proteasome inhibitors and apoptosis inducers in human leukemia cells. Biochem. Pharmacol. 2005, 69(10), 1421-1432. DOI:10.1016/j.bcp.2005.02.022.

4. Derangère, V.; Fumet, J.D.; Boidot, R.; Bengrine, L.; Limagne, E.; Chevriaux, A.; Vincent, J.; Ladoire, S.; Apetoh, L.; Rébé, C.; Ghiringhelli, F. Does bevacizumab impact anti-EGFR therapy efficacy in metastatic colorectal cancer? Oncotarget. 2016, 7(8): 9309-9321.

5. Evan, G.I.; Brown, I.; Whyte, M.; Harrington, E. Apoptosis and the cell cycle. Curr. Opin. Cell Biol. 1995, 7(6), 825 -834. doi.org/10.1016/0955-0674(95)80066-2.

6. Kalaiyarasu, T.; Karthi, N.; Mariyappan, P.; Manju, V.; Orientin, a flavanoid, mitigates 1, 2 dimethylhydrazine-induced colorectal lesions in wistar rats fed a high-fat diet. Toxicol Rep. 2018, 5, 977-987. https://doi.org/10.1016/j.toxrep.2018.09.004

7. Karthi, N.; Kalaiyarasu, T.; Kandakumar, S.; Mariyappan, P.; Manju, V. Pelargonidin induces apoptosis and cell cycle arrest via mitochondria mediated intrinsic apoptotic pathway in HT 29 cells. RSC Adv. 2016, 6, 45064-45076. DOI: 10.1039/C5RA20984F.

8. Kaufmann, SH.; Hengartner, MO. Programmed cell death: alive and well in the new millennium. Trends. Cell. Biol. 2001, 11(12):526-34. https://doi.org/10.1016/S0962-8924(01)02173-0.

9. Koelzer, J.; Pereira, D.A.; Dalmarco, J.B.; Pizzolatti, M.G.; Fröde, T.S. Evaluation of the antiinflammatory efficacy of Lotus corniculatus. Food Chem. 2009, 117(3), 444-450. DOI:10.1016/j.foodchem.2009.04.044.

10. Krishan, A. Rapid flow cytofluorometric analysis of mammalian cell cycle by propidium iodide staining. J. Cell. Biol. 1975, 66(1), 188-193. DOI: 10.1083 /jcb.66.1.188.

11. Kumari, S.; Badana, A.K.; Murali Mohan, G.; Shailender, G.; RamaRao, M. Reactive oxygen species: A key constituent in cancer survival. Biomark. Insights. 2017, 13, 1-9. https://doi.org/10.1177\%2F1177271918755391.

12. Liao, W.; Chen, L.; Ma, X.; Jiao, R.; Li, X.; Wang, Y. Protective effects of kaempferol against reactive oxygen species induced hemolysis and its anti proliferative activity on human cancer cells. Eur. J. Med. Chem. 2016, 114, 24-32. http://dx.doi.org/10.1016/j.ejmech.2016.02.045.

13. Miki, H.; Funato, Y. Regulation of intracellular signaling through cysteine oxidation by reactive oxygen species. J. Biochem. 2012 151(3): 255-61. https://doi.org/10.1093/jb/mvs006

14. Pelicano, H.; Carney, D.; Huang, P. ROS stress in cancer cells and therapeutic implications. Drug Resist. Updat. 2004, 7(2), 97-110. DOI:10.1016/j.drup.2004.01.004.

15. Phang, C.W.; Karsani, S.A.; Sethi, G.; Abd Malek, S.N. Flavokawain $\mathrm{C}$ inhibits cell cycle and promotes apoptosis, associated with endoplasmic reticulum stress and regulation of MAPKs and Akt signaling pathways in HCT 116 human colon carcinoma cells. PLOS ONE. $\mathbf{2 0 1 6 .}$ 
DOI:10.1371/journal.pone.0148775

16. Rajesh Kumar, S.; Priyatharshni, S.; Babu, V.N.; Mangalaraj, D.; Viswanathan, C.; Kannan, S.; Ponpandian, N. Quercetin conjugated superparamagnetic magnetite nanoparticles for in-vitro analysis of breast cancer cell lines for chemotherapy applications. J. Colloid. Interface Sci. 2014, 436, 232-242. http://dx.doi.org/10.1016/j.jcis.2014.08.064.

17. Rupnarain, C.; Dlamini, Z.; Naicker, S.; Bhoola, K. Colon cancer: genomics and apoptotic events. Biol. Chem. 2004, 385, 449-64.

18. Siegel, R.L.; Miller, K.D.; Jemal, A. Cancer Statistics. CA Cancer. J. Clin. 2019, 69, 7-34.

19. Varshney, R.; Varshney, R.; Mishra, R.; Gupta, S.; Sircar, D.; Roy, P. Kaempferol alleviates palmitic acid-induced lipid stores, endoplasmic reticulum stress and pancreatic $\beta$-cell dysfunction through AMPK/mTOR-mediated lipophagy. J. Nutr. Biochem. 2018 57, 212-217. https://doi.org/10.1016/j.jnutbio.2018.02.017.

20. Vijayalakshmi, A.; Sindhu, G. Umbelliferone arrest cell cycle at G0/G1 phase and induces apoptosis in human oral carcinoma (KB) cells possibly via oxidative DNA damage. Biomed. Pharmacother 2017, 92, 661-671. doi.org/10.1016/j.biopha.2017.05.128.

21. Vivek, R.; Ramar, T.; Muthuchelian, K.; Gunasekaran, P.; Kaveri, K.; Kannan, S. Green biosynthesis of silver nanoparticles from Annona squamosa leaf extract and its in vitro cytotoxic effect on MCF-7 cells. Process Biochem. 2012, 47(12), 2405-2410. http://dx.doi.org/10.1016/j.procbio.2012.09.025.

22. West, N. R.; McCuaig, S.; Franchini, F.; Powrie, F. Emerging cytokine networks in colorectal cancer. Nat. Rev. Immunol. 2015 , 15(10), 615-629. DOI:10.1038/nri3896.

23. Xu, Y.C.; Leung, S.W.; Leung, G.P.; Man, R.Y. Kaempferol enhances endothelium-dependent relaxation in the porcine coronary artery through activation of large-conductance $\mathrm{Ca}(2+)$ - activated $\mathrm{K}(+)$ channels. Br. J. Pharmacol. 2015, 172, 3003-3014. DOI:10.1111/bph.13108

24. Zhang, J.; Zhi, X.; Shi, S.; Tao, R.; Chen, P.; Sun, S.; Bian, L.; Xu, Z.; $\mathrm{Ma}, \mathrm{L}$. POCK1 is up-regulated and promotes tumor growth via the $\mathrm{PI} 3 \mathrm{~K} / \mathrm{AKT}$ signaling pathway in colorectal cancer. Biochem. Biophys. Res. Commun. 2016, 482(4), 870-876. DOI: 10.1016/ j.bbrc.2016.11.126

25. Zhu, H.; Lv, G.; Qu, Q.; Xu, J.; Zhang, L.; Zhu, Y. Thunder god vine extract exerts antiproliferative effects on growth of human colon cancer cells and inhibits colon cancer growth in xenograft mice

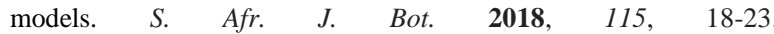
https://doi.org/10.1016/j.sajb.2017.12.005. 